therapist must again direct the family to confront their avoidance and help clarify each member's responsibility for the decision. If a court orders residential placement, the therapist can return the responsibility for the decision-making process to the family by asking, for example, whether family members disagree with the judge or how they managed to convince the judge that residential treatment was the best thing for everyone.

Although the patient's siblings need to be protected from being put into the position of making the decision, the nature of the sibling relationships and the meaning of the loss to each sibling should be explored. Siblings' own fears of abandonment and their guilt about sibling rivalries can be exacerbated by a decision for residential placement.

Once a family has made a decision for residential treatment, two separate processes begin. First, the family, social service agencies, and the hospital evaluation team must select a specific treatment program based on the amount of structure and the type of treatment indicated as necessary from the evaluation (7). The family cannot be expected to know how the referral system works and will need assistance in working with the variety of agencies involved and selecting the appropriate treatment program. The second process, which is clinical, has been described as the anticipatory mourning process (8). Through it, the family and adolescent prepare for the actual separation.

\section{References}

1. Byng-Hall J, Bruegen P: Pamily admission decisions as therapeutic tool. Family Process 13:443-459, 1974

2. Solomon MA: Resistance in family therapy: some conceptual and technical considerations. Family Coordinator 23:159-163, 1974

3. Solomon MA: The staging of fumily treatment: an approsch to developing the therapeutic alliance. Journal of Marriage and Bamily Counceling 4:3966,1977

4. Blanck G, Blanck RH: Ego Poycholooy: Theory and Practice. New York,
Columbia University Press, 1974

5. Minuchin S: Families and Family Therapy. Cambridge, Mass, Harvard University Press, 1974

6. Farley JE: Family separation-individuation tolerance: a developmental conceptualization of the nuclear family. Journal of Marital and Family Therapy 5:61-66, 1979
7. Easson WM: The severely disturbed adolescent: inpatient, residential, and hospital treatment. New York, International Universities Press, 1969

8. Farley JE: Preparation for residential treatment: an anticipatory mourning process. Clinical Social Work 12:3142,1984

\title{
Staff Reaction to an Inpatient Homicide
}

\section{Francine Cournos, M.D.}

The hospital management of the violent patient has received increasing attention in recent years. The occurrence of a homicide on the acute psychiatric inpatient unit of a large public hospital in New York City provided a painful example of the largely unexplored effects on the staff of a specific act of patient violence.

\section{Case report}

One night Mr. A, a black man in his twenties, was brought by police to the emergency room of the hospital after brandishing a knife in front of his family. Mr. A had been admitted to the hospital's 18-bed acute admitting unit twice previously because of psychosis and suicidal behavior. His diagnosis was paranoid schizophrenia.

Mr. A's suicide attempts involved severe self-mutilation in which he lacerated his wrists, neck, and penis with a knife. He had extensive training in karate as well as the typical constellation that predicts violence: he was a young

Dr. Cournos is assistant clinical professor of psychiatry at the College of Physicians and Surgeons of Columbia University and director of Washington Heights Community Services at New York State Psychiatric Institute, 722 West 168th Street, New York, New York 10032. male with low self-esteem, a history of drug and alcohol abuse, a criminal record, and past episodes of self-mutilation. However, he had no known history of actual physical assault.

Mr. A's third admission to the ward occurred at 2 a.m. He was seen by the psychiatric resident on call, given $100 \mathrm{mg}$ of oral chlorpromazine, and placed on constant observation. Mr. A sat quietly and talked softly to the night staff, who judged him to be in control at that time. After a while Mr. A went to bed but was unable to sleep.

At about 6 a.m. he got up and was observed in the ward area ad. jacent to the nurses' station. Mrs. B, 67-year-old, severely depressed, frail Caucasian woman, sat moaning nearby. Mr. A began to pace, and the nurse on duty decided to medicate him. While she was preparing the medication, Mr. A suddenly grabbed Mrs. B and threw her to the floor. Using karate-like motions, he kicked her head and chest. The female staff members who witnessed the event felt unable to restrain the patient and immediately summoned the only male therapy aide on duty. He arrived with three male patients, and they placed Mr. A in seclusion without resistance. Mrs. $B$ died almost instantly.

After the attack Mr. A was disoriented and stared wildly. He did not speak coherently for several hours. When he was told what had 
happened, Mr. A said, "I'm sorry. I'm very confused." He remained in seclusion until he was transferred to a criminal facility later in the day.

\section{Staff reaction}

A series of staff meetings was held to discuss staff members' feelings about the homicide and possible ways to prevent violence in the future. The initial staff meeting focused primarily on where to place blame for the murder. Staff members on all three shifts expressed the fear that another murder could occur at any time. Almost everyone felt that the ward was an unsafe place and that staff members were unfairly being asked to risk their lives.

Staff reactions were in marked contrast to the patients' reactions articulated during ward meetings. Patients were able to review the details of the homicide, discuss their own fears of aggression, express concern and sadness for Mr. $A$, and talk about the tragic death of Mrs. B. These topics were rarely brought up at staff meetings. Patients felt that an incident of this sort was unpredictable and extremely unlikely to happen again and that the ward was still generally safe. Neither patients nor staff members mentioned the race of the victim or the attacker.

The staff was preoccupied with the homicide for months, and the topic dominated staff discussion, while voluntary patients continued to seek admission to the unit and only occasionally expressed fears about their safety. The incidence of violent behavior among patients remained low, as always.

Typical staff reactions included the following:

- Several members of the night staff announced that they would never venture into any ward area except in pairs.

- Several female therapy aides demanded a staffing change that would provide a male aide for each male patient.

- Physicians were constantly concerned about whether patients were sufficiently sedated.
- Psychiatric residents began shouting during staff meetings after minor provocations.

- The psychiatrist who was on duty at the time of the murder experienced symptoms of depression, including insomnia, anorexia, and weight loss.

- Several nursing staff members resigned suddenly.

$\Lambda$ high degree of disturbance persisted for months in spite of numerous staff meetings held in an attempt to work through these feelings.

\section{Discussion}

This case study reports a much more dramatic degree of staff disturbance in reaction to an episode of patient violence than has generally been reported.

The literature describing the impact of violence on staff is limited. Turns and Gruenberg (1) discussed an incident in which a patient murdered an attendant. They did not report any particular staff disturbances, although staff reaction was not the primary focus of their paper. Straker and associates (2) studied inpatient assaults, primarily against staff, and found that staff members felt tense, guilty, and concerned about the appropriateness of their responses to violence.

Lanza (3) studied the effects of patient assaults on the nursing staffs of both psychiatric and medical wards. Victims typically reported minimal emotional reactions to being assaulted, although a few staff members reported long-term anger and anxiety. Lanza suggested that perhaps staff members were afraid of being overwhelmed by their feelings and believed that being assaulted had to be accepted as part of the job. Cotton and others (4) described the reactions of ward staff members to inpatient suicide and reported an initial phase of shock followed by a wide range of emotional reactions, including rage, guilt, anxiety, depression, self-doubt, and anger.

What accounted for the staffs high degree of distress and sense of passive victimization in re- sponse to this particular incident? Common formulations maintain that staff members may precipitate violence by appearing overly fearful, which suggests that they cannot control violence, or by being overly authoritative, implying that that they expect it $(5,6)$. These psychological formulations suggest that a safe environment can always be attained if the staff function optimally.

A public inpatient service can in fact be an unsafe place, due to staffing limitations, lack of control over admissions, the mixing of physically strong with physically weak patients, and unusual situations such as the one reported here-the admission of a patient specifically skilled in karate. These factors are exacerbated on an acute admitting unit.

Wards that work under the constant pressure of a high turnover and that handle acutely disturbed and involuntary patients may have more difficulty resolving trauma than units with a more stable, longterm population (7). An acute care unit is much less of a community than a long-term ward, and violence seems more random (8). The homicide committed by Mr. A disrupted the confidence staff had in their ability to manage violence and threatened their belief that the controlled hospital setting offered patients a safe environment $(9,10)$.

Following the incident, the unit searched for additional techniques to prevent future violence. The recommendations that were implemented included additional training in the timely use of medication and in the prediction, prevention, and management of violence. The hospital now tries to avoid placing frail, elderly patients on wards with young, violent patients.

The staff felt helpless to perform the tasks expected of them-to control a violent patient and protect a frail one-and as a result suffered severe reactions to the homicide and a sense of victimization. It is hoped that the hospital's implementation of techniques to predict, prevent, and control violence will lead to a safer inpatient 
environment. However, even the best-trained staff on a well-run ward have their limitations, and it is important for policymakers to keep in mind the practical problems involved in managing violent patients.

\section{Acknowledgments}

The author thanks Ethel Person, M.D., and Steven Roose, M.D., for their comments on the manuscript, and Audrey Shannon for manuscript preparation.

\section{References}

1. Turns DM, Gruenberg EM: An attendant is murdered: the state hospital responds. Psychiatric Quarterly 47:487-494, 1973

2. Straker M, Carman P, Fulton J, et al: Assaultive behaviors in an institutional setting. Psychiatric Journal of the University of Ottawa 2:185-189, 1977

3. Lanza ML: The reactions of nursing staff to physical assault by a patient.
Hospital and Community Psychiatry 34:44-47, 1983

4. Cotton PG, Drake RE, Whitaker A, et al: Dealing with suicide on a psychiatric inpatient unit. Hospital and Community Psychiatry 34:55-59, 1983

5. Cornfield RB, Fielding SD: Impact of the threatening patient on ward communications. American Journal of Psychiatry 137:616-619, 1980

6. Levy P, Hartocollis P: Nursing aides and patient violence. American Journal of Psychiatry 133:429-431, 1976

7. Rosen H: The impact of the psychiatric intensive-care unit on patients and staff. American Journal of Psychiatry 132:549-551, 1975

8. Quinsey VL: Studies in the reduction of assaults in a maximum security psychiatric institution. Canada's Mental Health 25:21-23, 1977

9. Rogers R, Ciula B, Cavanaugh JL: Aggressive and socially disruptive behavior among maximum security psychiatric patients. Psychological Reports 45:291-294, 1980

10. Di BW: Educating staff to manage threatening paranoid patients. American Journal of Psychiatry 136:333335,1979

\section{A Geriatric Nutrition Program Designed to Improve Independence in Feeding}

Joanne Nangeroni, R.D. Philip S. Pierce, Ph.D.

As the number of elderly people in the United States increases, more attention is being focused on the problems associated with providing good nutrition to aged patients. According to U.S. census data, there are currently 32,000 people over the age of 100 and approximately 25 million over age 65 (1).

Ms. Nangeroni is clinical dietitian with the dietetic service and Dr. Pierce is chief of the psychology service at the Veterans Administration Medical and Regional Office Center, Togus, Maine 04330.
Factors such as weakened physical condition, lower social and economic status, and poor mental health place many members of the elderly population at high risk for malnutrition (2-5). The institutionalized elderly are particularly susceptible to malnutrition, since they are often severely regressed patients who suffer from $\mathrm{Alz}$ heimer's disease, senile dementia, tardive dyskinesia, multiple sclerosis, Huntington's chorea, and other physical and mental disorders that affect eating behavior (6). A majority of these patients require assistance in eating.

The physical and psychiatric disabilities of these patients can prevent them from consuming an adequate diet and can create a vicious cycle in which the decreased intake of nutrients causes additional mental and behavioral changes such as increased weakness, apathy, anxiety, anorexia, and depression $(3,7)$.

\section{The nutrition program}

Nearly 37 percent of our medical center's 633 beds are designated primarly for elderly disabled patients. They include 60 beds on the nursing home unit, 60 beds on the psychogeriatric unit, and 121 beds on the intermediate care unit.

We wanted to improve the nutritional status of our psychogeriatric patients by developing an innovative diet that would enhance the patients' independence in feeding themselves. The menu would consist of a variety of soft-textured foods that could be easily grasped and eaten with the fingers, so that patients with poor finger dexterity, poor fine motor movements, severe tremors, and other factors affecting eating behaviors could learn to eat with greater ease and with less assistance from others. We hoped the diet would be better tolerated, more aesthetically pleasing, more palatable, and more easily managed than the usual mechanical (ground) or pureed diet for these patients.

Our ultimate goal was to increase the patients' quality of life and personal dignity by providing a diet that facilitates independence in eating.

Thirty psychogeriatric patients residing on an intermediate care unit were targeted as possible candidates for the geriatric nutrition program. All were screened to determine if they were at nutritional risk. Criteria for selection were feeding disabilities that prevented an adequate food intake (for example, poor hand and finger coordination, tremors, flailing, dysarthria, poor dentition, high degree of distractibility, and limited concentration); current placement on a pureed or mechanical diet; and minimal or marginal self-feeding ability.

Twenty-two patients, or 73 percent, met the selection criteria. All 